\title{
mtDNA singletons as evidence of a post-invasion genetic bottleneck in yellowfin goby Acanthogobius flavimanus from San Francisco Bay, California
}

\author{
Matthew E. Neilson ${ }^{1,2}$, Raymond R. Wilson $\mathrm{Jr}^{1, *}$ \\ ${ }^{1}$ Department of Biological Sciences, California State University, Long Beach, 1250 Bellflower Boulevard, Long Beach, \\ California 90840, USA \\ ${ }^{2}$ Present address: Great Lakes Genetics Lab, Lake Erie Center, University of Toledo, 6200 Bayshore Road, Oregon, \\ Ohio 42618, USA
}

\begin{abstract}
Yellowfin goby, a fish native to East Asia, was first reported in northern California (San Francisco Bay) in 1963 and in southern California (Los Angeles Harbor) in 1979. Over the past 4 decades, it has spread to other northern and southern California estuaries, respectively. The documented expansion of yellowfin goby in California provided an opportunity to study potential founder effects in a marine invasive fish by seeking evidence of reductions in mtDNA singleton haplotypes consistent with an expected loss of overall genetic diversity. We obtained samples of yellowfin goby from San Francisco Bay in northern California, from 2 small estuaries in southern California, and from Tokyo Bay, Japan, the presumed source population. The mtDNA control region was fully sequenced and analyzed for a total of 216 specimens, where the numbers of singleton haplotypes relative to the total number of haplotypes in each sample were compared to predictions from a regression analysis of singletons on total haplotypes. AMOVA comparisons among haplotype frequencies were also performed. Singleton haplotypes were significantly fewer than predicted among yellowfin goby of San Francisco Bay, indicating some loss of genetic diversity in that invasive population. Singletons were not significantly fewer than prediction among yellowfin goby of Tokyo Bay or of southern California. $\Phi_{\text {ST }}$ values were not significantly different between San Francisco and Tokyo bays, but were different between San Francisco Bay in northern California and southern California locations, suggesting separate introductions to California.
\end{abstract}

KEY WORDS: Gobiidae $\cdot$ Haplotype diversity $\cdot$ Marine colonization $\cdot$ Estuarine invasions

\section{INTRODUCTION}

The demographic and genetic consequences of recent population genetic bottlenecks are of interest to marine ecologists, conservation biologists, and population geneticists alike, with ever growing numbers of marine species facing severe reductions in population size (Myers \& Worm 2003). Population genetic bottlenecks are caused by significant, if temporary, reductions in genetic effective size that can cause reduction of genetic diversity through loss of DNA polymorphism (Tajima 1989), expressed as loss of heterozygosity (Nei et al. 1975), or loss of alleles (Maruyama \& Fuerst 1985) at a locus. Genetic bottlenecks are natural phenomena that can occur over the evolutionary history of a species, where lost diversity is eventually regenerated through new mutations and population growth, and where extant species exist at various interim stages in the process (Hewitt 2000). Bottlenecks likely resulting in loss of genetic diversity can be anthropogenically forced through overexploitation (Hoelzel 1999, Hauser et al. 2002) or through destruction of critical breeding or foraging habitat (Gibbs 2001, Jager et al. 2001).

Detection of a recent genetic bottleneck from population-genetic data requires an index sensitive to the type of influences that accompany them. An index 
based on chromosomal alleles would be advantageous due to the large body of population-genetic theory available, and because models of the expected behaviors of nuclear alleles following a bottleneck have been well described (Nei et al. 1975, Chakraborty \& Nei 1977, Watterson 1984, Maruyama \& Fuerst 1985). Alleles at microsatellite loci have particular utility because of their high polymorphism (Tautz 1989) and high mutation rate (Weber \& Wong 1993). Several tests have been created to detect genetic bottlenecks from distortion of microsatellite allele frequencies (e.g. Cornuet \& Luikart 1996, Luikart et al. 1998). Recently, Garza \& Williamson (2001) described a test that utilizes the ratio of the number of alleles to the range in allele size for microsatellite loci. Those methods, however, require relatively high amounts of polymorphism (at least 5 alleles per locus/5 to 20 loci) for power and new development of those markers is labor-intensive.

Mitochondrial DNA (mtDNA) has been widely used in population genetic studies, particularly among marine fishes (e.g. Bernatchez et al. 1989, Tringali \& Wilson 1993, Goodbred \& Graves 1996, Gold et al. 1997, Stepien \& Faber 1998, Stepien et al. 2000, Wirgin et al. 2000, Bernatchez 2001). The chief indices of mtDNA polymorphism, nucleotide and haplotype diversity (Nei 1987), can be determined from RFLP analysis or from direct sequencing. The expected reductions in those indices following a bottleneck (Watterson 1984, Tajima 1989) have been used to explain contemporary patterns of mtDNA diversity in fishes. However, among marine fishes, there exists such wide variation in those indices (Bernatchez et al. 1989, Grant \& Bowen 1998) that interpretation of any single set of values for a given population is subjective.

Luzier \& Wilson (2004) recently considered the percentage of single-copy mtDNA haplotypes (singletons) in a sample as a potential index for identifying transitory reductions in female genetic effective size. Their approach was based on the recognition that when female effective size $\left(\mathrm{N}_{\mathrm{ef}}\right)$ falls dramatically, effectively creating a population-genetic bottleneck, the proportion of mtDNA singleton haplotypes recoverable from sampling will fall below what is usual for large stablesize populations at mutation-drift equilibrium (Kimura \& Crow 1964). Among marine fishes, the usual haplotype distribution is one of few in medium to high frequencies, with most occurring in low frequencies or in single copy numbers (Luzier \& Wilson 2004).

To further examine the relative occurrences of singletons in natural populations of marine fishes, we reassembled data from genetic studies for 13 species that used mtDNA control region sequences as a genetic marker (Sang et al. 1994, Bowen \& Grant 1997, Stepien 1999, Stepien et al. 2000, Riginos \& Nachman 2001, Dawson et al. 2002, Kai et al. 2002, Ovenden \& Street 2003, Stefanni \& Thorley 2003), from fish populations believed or known to be very large (Table 1). Once again, we found the large majority of all discovered haplotypes to be singletons. A least-squares regression similar to that of Luzier \& Wilson (2004) revealed that the number of singletons increased in proportion to total haplotypes discovered with increasing sample size (Fig. 1). If the samples from the prior studies were indeed drawn from large populations at mutation-drift equilibrium that had not lost genetic diversity from

Table 1. Occurrence of singleton mtDNA control region haplotypes in natural populations of marine fishes. Sample size (N) is the number of fish sequenced in each study. $\mathrm{H}_{\mathrm{T}}$ : total number of haplotypes discovered in each study; $\mathrm{H}_{\mathrm{S}}$ : number of singleton haplotypes discovered. Haplotype $(h)$ and nucleotide $(\pi)$ diversity are calculated for the entire data set in each study. Data are those used to generate the regression line of Fig. 1

\begin{tabular}{|lccrrrrrl}
\hline Species & $\mathrm{N}$ & $\begin{array}{c}\text { No. bases } \\
\text { sequenced }\end{array}$ & $\mathrm{H}_{\mathrm{T}}$ & $\mathrm{H}_{\mathrm{S}}$ & $\mathrm{H}_{\mathrm{S}} / \mathrm{H}_{\mathrm{T}}$ & $h$ & $\pi$ & Source \\
\hline Sardinops spp. & 81 & 500 & 78 & 77 & 0.987 & 0.998 & 0.051 & Bowen \& Grant (1997) \\
Pomatoschistus minutus & 51 & 762 & 38 & 31 & 0.816 & 0.980 & 0.011 & Stefanni \& Thorley (2003) \\
Pomatoschistus lozanoi & 6 & 762 & 5 & 4 & 0.800 & 0.933 & 0.006 & Stefanni \& Thorley (2003) \\
Clevelandia ios & 66 & 523 & 65 & 64 & 0.985 & 0.999 & 0.012 & Dawson et al. (2002) \\
Lutjanus argentimaculatus & 34 & 375 & 33 & 32 & 0.970 & 0.998 & n/a & Ovenden \& Street (2003) \\
Anguilla japonica & 31 & 487 & 30 & 29 & 0.967 & 0.998 & 0.015 & Sang et al. (1994) \\
Microstomus pacificus & 110 & 373 & 90 & 83 & 0.922 & 0.992 & 0.014 & Stepien (1999) \\
Microstomus achne & 11 & 373 & 6 & 3 & 0.500 & $\mathrm{n} / \mathrm{a}$ & $\mathrm{n} / \mathrm{a}$ & Stepien (1999) \\
Sebastolobus alascanus & 93 & 443 & 83 & 79 & 0.952 & 0.990 & 0.015 & Stepien et al. (2000) \\
Sebastolobus altivelis & 55 & 444 & 43 & 39 & 0.907 & 0.960 & 0.009 & Stepien et al. (2000) \\
Sebastolobus macrochir & 14 & 443 & 14 & 14 & 1.000 & 1.000 & 0.016 & Stepien et al. (2000) \\
Sebastes inermis & 61 & 375 & 46 & 40 & 0.870 & 0.980 & 0.013 & Kai et al. (2002) \\
Axoclinus nigricaudus & 105 & 408 & 86 & 77 & 0.895 & 0.994 & n/a & Riginos \& Nachman (2001) \\
Paralabrax clathratus & 39 & 423 & 24 & 20 & 0.833 & 0.924 & 0.005 & Luzier \& Wilson (2004) \\
Gillichthys mirabilis & 31 & 883 & 28 & 26 & 0.929 & 0.991 & 0.017 & E. Armour \& R.R.W. (unpubl.) \\
\hline
\end{tabular}




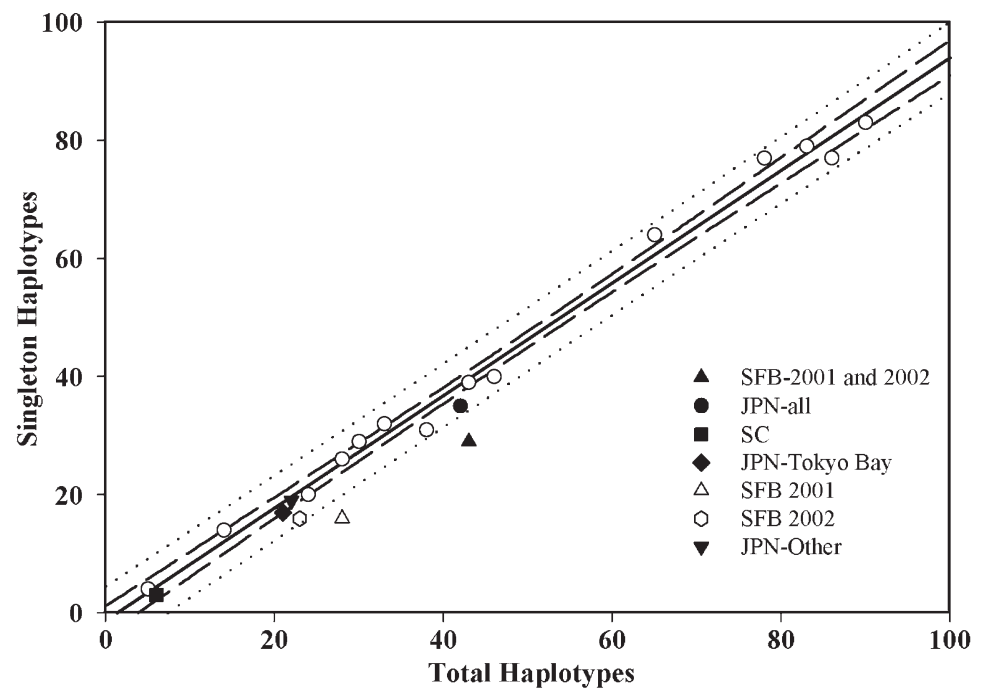

Fig. 1. Acanthogobius flavimanus. Least-squares linear regression of singleton versus total haplotypes discovered from population sampling. The regression equation is: $y=0.953 x-1.31 ; \mathrm{r}^{2}=0.99$. 0 : data from individual studies listed in Table 1, used to calculate regression line. Solid line: the regression; dashed lines: 95\% confidence intervals of the regression slope; dotted lines: $95 \%$ prediction intervals for new data observations. Filled symbols, open triangle, and open hexagon: new data observations from California and Japan populations of yellowfin goby. SFB: San Francisco Bay; SC: southern California; JPN-all: Japan, all locations; JPN-other: Miyagi and Fukushima lowfin goby common throughout SFB (Brittan et al. 1970). In southern California, Haaker (1979) discovered a second population of yellowfin goby in Los Angeles Harbor (Fig. 2). The southern California population of A. flavimanus now extends into Bolsa Chica and the upper Newport Bay estuary as well as into San Diego Bay (Fig. 2) and its surrounding salt marsh, and possibly into Baja California (Williams et al. 1998). Whereas yellowfin goby is now widespread in southern California, it is not especially common.

Northern and southern California may have experienced separate introductions evidenced by the temporal (ca. $16 \mathrm{yr}$ ) and spatial (ca. $650 \mathrm{~km}$ ) separation of the initial reports. Moreover, the appearance of individuals in areas of southern California that have not received direct trans-Pacific shipping from Asia suggests that the range expansion there was by self propagation. The dramatic expansion in San Francisco Bay also largely suggests a selfsustaining population, but one that may occasionally be receiving some new immigration from East Asia.

The colonization and expansion history of 2 populations of Acanthogobius flavimanus in California as reported, presents a good demorecent bottlenecking, it would be possible to predict the $y$ number of singletons expected from $x$ distinct mtDNA haplotypes discovered in a sample.

Invasive (i.e. colonizing) marine species might present good cases with which to study genetic bottlenecking using mtDNA singleton analysis. Recent surveys have found over 600 introduced or cryptogenic aquatic taxa along the California coast including 250 in the San Francisco Bay estuary system (Cohen \& Carlton 1998). Whereas some introductions have been intentional, such as for fisheries enhancement (Baltz 1991), many, such as colonization of San Francisco Bay by yellowfin goby, have occurred unintentionally through ballast water from transoceanic shipping vessels (Carlton \& Geller 1993).

Yellowfin goby Acanthogobius flavimanus (Temminck \& Schlegel) is a large (up to $215 \mathrm{~mm}$ total length) estuarine fish native to NE Asia, typically inhabiting muddy bottoms of bays, estuaries, and rivers (Lever 1996). Two geographic populations were recently established along the northern and southern coast areas of California, supposedly through ballast-water transport of eggs or larvae (Baltz 1991). In northern California, Brittan et al. (1963) first reported A. flavimanus from the Sacramento River delta which feeds into San Francisco Bay (SFB). By 1968, the population had experienced a dramatic expansion making yelgraphic model system against which to test the prediction of a reduced occurrence of rare mtDNA necking attended the colonization. To do so, we used sequences of the mtDNA control region of $A$. flavimanus to identify haplotypes present among specimens from northern and southern California, and from native Japan. If the 2 California populations are genetically isolated, and have experienced 2 separate and independent bottlenecks during colonizapredicted number of singleton haplotypes for each population as well as from significant differences in haplotype composition and frequencies. If no significant reduction in singleton haplotypes is seen, and no differences among haplotype frequencies are found, there would be no evidence for a founder event or genetic bottleneck. In such a case, the California and Japan populations might represent a panmictic population.

\section{MATERIALS AND METHODS}

Specimen collection. In northern California, yellowfin goby were collected principally between July and December of 2001 and 2002 from sites throughout haplotypes in colonizing populations if genetic bottletion, it should be evident from deviations from the 
a

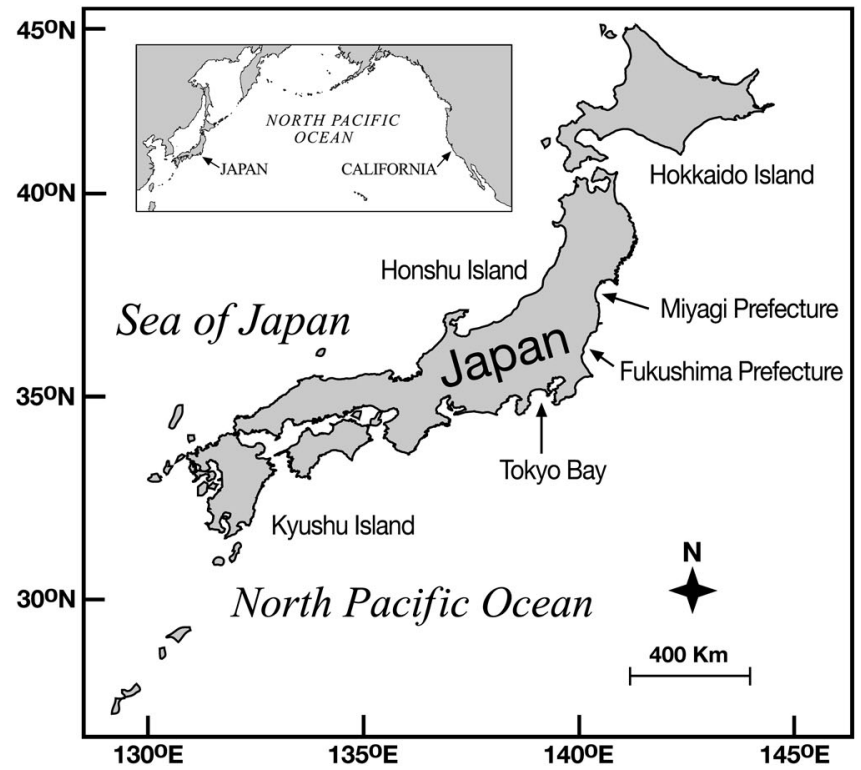

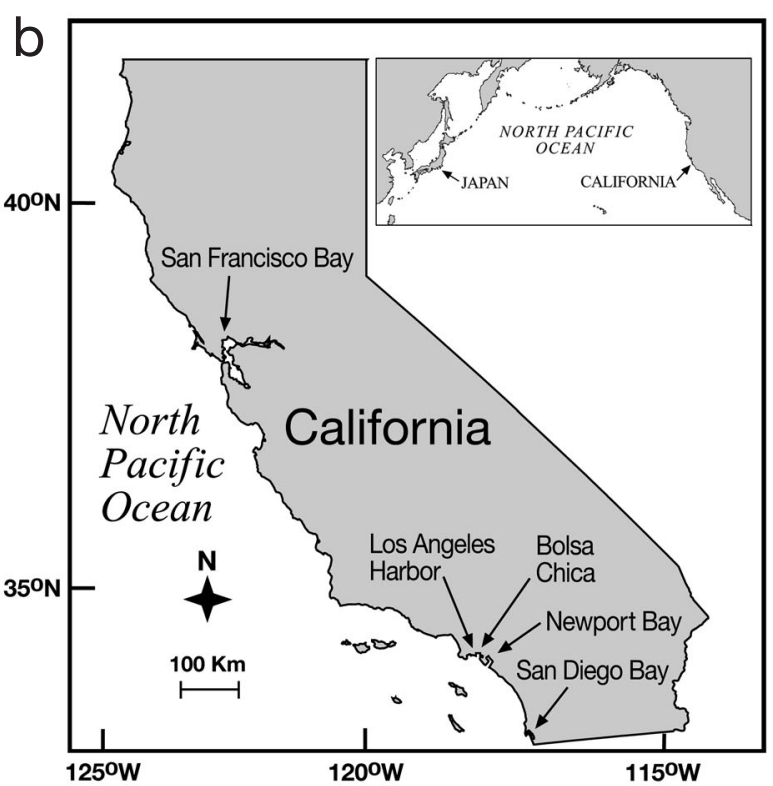

Fig. 2. (a) Locations of 3 collection areas for yellowfin goby in Japan. The sample from Tokyo Bay was taken in the lower (tidal) portion of the Tama River (river not indicated on map), which flows into Tokyo Bay; yellowfin goby from Miyagi and Fukushima prefectures were acquired from fish vendors. (b) Locations of collection areas for yellowfin goby in California. Northern California samples were taken in San Francisco Bay; southern California samples were taken in Bolsa Chica and the upper portion of Newport Bay. Collections were attempted in Los Angeles Harbor and San Diego Bay but were unsuccessful

SFB with bottom trawls and beach seines. Specimens were obtained chiefly through the San Francisco Bay Study, California Department of Fish and Game (CDFG), and the Interagency Ecological Program for the San Francisco Estuary; 43 specimens in 2001 and 44 in 2002. The specimens were collected during regular survey of 79 sites along a $200 \mathrm{~km}$ transect from South San Francisco Bay to the Sacramento River. The CDFG sampling grid can be viewed at www. delta.dfg.ca.gov/baydelta/monitoring/baystudy.asp. The CDFG collections were augmented with 21 specimens collected from the northern portion of SFB in 2001.

In southern California between June 2002 and April 2003, we collected specimens using small beach seines and baited traps from Bolsa Chica (= BC) and upper Newport Bay (= UNB), 2 estuaries separated by about $20 \mathrm{~km}$ (Fig. 2). Most fish caught in 2003 were small $(<10 \mathrm{~cm})$, representing newly recruited individuals. Specimens were chosen from that group for sequencing using a random number table. Several attempts to obtain population samples from Los Angeles Harbor and its vicinity, and San Diego Bay (Fig. 2) were unsuccessful.

In August of 2003, we obtained comparative samples from within the native East Asian range of yellowfin goby. One sample of 55 specimens was taken in August 2003 from the lower Tama River (35³2.496' N, $\left.139^{\circ} 44.508^{\prime} \mathrm{E}\right)$, which flows into Tokyo Bay of Honshu
Island, Japan (Fig. 2). Two additional samples were obtained at the same time from Tokyo fish vendors from 2 localities in the Tohoku District of northern Honshu Island, the Miyagi (31 specimens) and Fukushima (41 specimens) prefectures (Fig. 2). The origins of the vended specimens were provided to us by Dr. K. Sakamoto, Curator, Tsukiji Wholesale Market Museum, Tokyo, Japan. Specimens we collected expired in the field on wet ice, and were preserved either by storage at $-86^{\circ} \mathrm{C}$ or fixation in $70 \%$ ethanol.

DNA extraction, PCR amplification, and sequencing. Total genomic DNA was extracted from $25 \mathrm{mg}$ of white muscle tissue using a DNEasy Tissue Extraction Kit (QIAGEN). PCR amplification of the mtDNA control region was performed in a volume of $100 \mu \mathrm{l}$ with the following reaction conditions: dNTPs $(200 \mu \mathrm{M}$ each), $50 \mathrm{mM} \mathrm{KCl}, 10 \mathrm{mM}$ Tris $\mathrm{pH} 8.3,1.5 \mathrm{mM} \mathrm{MgCl}_{2}$, $0.01 \%$ gelatin, $0.05 \%$ Triton X-100, PCR primers $(1.8 \mu \mathrm{M}$ each) (forward: 5'-TCCCATCTCTAGCTCCCAAA-3'; reverse: 5'-TACGTTGGCGTGTGCATTAT-3'), 2 units of Taq polymerase, and $30 \mathrm{ng}$ of template DNA. The cycling profile included initial denaturation at $94^{\circ} \mathrm{C}$ for $4.5 \mathrm{~min}$, followed by 35 cycles of $94^{\circ} \mathrm{C}$ for $50 \mathrm{~s}, 55^{\circ} \mathrm{C}$ for $40 \mathrm{~s}$, and $72^{\circ} \mathrm{C}$ for $1.5 \mathrm{~min}$, and final extension at $72^{\circ} \mathrm{C}$ for $5 \mathrm{~min}$. PCR products $(\sim 1.1 \mathrm{~kb})$ were visualized on $1.2 \%$ TAE-agarose gels, and either gel-purified and ethanol-precipitated (Sambrook et al. 1989) or concentrated using Microcon PCR centrifugal filtration 
devices (Millipore). Purified PCR products were bidirectionally sequenced at $61^{\circ} \mathrm{C}$ using 2 pairs of fluorescently labeled sequencing primers (CR3-R 5'GTTAAGCCCGGGGTAAGTTT-3' and CR5-F 5' CCCAAAGCTAGTATTCTGGTTTAACT-3'; CR4-F 5' GAACATTTCCTTGCATTCTCG-3' and CR6-R 5'AGAGTGAACGCTTGGCATGT-3') and a SequiTherm EXCEL II sequencing kit (Epicentre). Sequencing reactions were resolved on $0.2 \mathrm{~mm}$ thick, $5.5 \%$ polyacrylamide gels and read using a LI-COR IR2 4200L DNA sequencer and eSeq v2.0 automated sequencing software (LI-COR).

Sequence and population analyses. For each individual, forward and reverse sequences from both sequencing reactions were aligned using AlignIR (LI-COR) to generate the complete control region sequence. Control region sequences for all individuals were then aligned using MegAlign (DNAStar), and haplotypes determined by the number of polymorphic nucleotide sites among all sequences. For each population sample, singleton haplotypes were defined as haplotypes appearing once in that sample. We calculated haplotype $(h)$ and nucleotide $(\pi)$ diversities (Nei 1987) for each population from full sequences using Arlequin version 2.000 (Schneider et al. 2000). For closer comparability with the regression (Fig. 1), we also calculated those indices for reduced datasets, using 504 and 320 nucleotides from the left domain of the control region, which generally has higher variability than the central and right domains in teleosts. Tests for heterogeneity of haplotype frequencies among samples taken at different localities or in different years within a locality were performed using a Monte Carlo randomization procedure (Roff \& Bentzen 1989) with 1000 randomizations implemented in CHIRXC (Zaykin \& Pudovkin 1993) from full sequences only. A sequential Bonferroni correction (Rice 1989) was used to adjust significance levels for multiple tests.

An analysis of molecular variance (AMOVA) implemented in Arlequin (Excoffier et al. 1992, Schneider et al. 2000) was used to identify geographic patterns in population structure. Genetic distances among haplotypes were calculated using Tamura (1992) distances with a gamma distribution shape parameter $(\alpha)$ of 1.2549. AMOVA uses a nested analysis of variance framework to partition the total amount of genetic differentiation between hierarchical levels of population subdivision (Weir 1996), producing $\Phi$-statistics that measure the similarity of pairs of haplotypes in each hierarchical level of the analysis, relative to pairs drawn from the pool of sequences in the next higher level. Significance of the $\Phi$-statistics is tested by permuting haplotypes among the corresponding hierarchical levels, and recalculating the statistics to obtain their null distributions (Excoffier et al. 1992). Sequence divergence among populations was also investigated by estimating the average number of nucleotide differences between populations (Nei \& Li 1979, Schneider et al. 2000). Significance of the estimated divergences was tested in a randomization procedure similar to that for AMOVA.

To test for a reduced number of singleton haplotypes, we determined the number of singletons predicted for the total number of haplotypes discovered in each population using the regression equation in Fig. 1 as in Luzier \& Wilson (2004). The standard error $\left(\hat{S}_{Y}\right)$ of the predicted number of singletons $\left(\mathrm{H}_{\mathrm{S}}\right)$ was calculated following Sokal \& Rohlf (1981), and is similar to the method for calculating the prediction interval for a given $\alpha$ level around a regression line. Prediction intervals around a regression line are from the $t$-distribution so the observed and predicted values for singletons were compared using a 1 -sample $t$-test with $n-2$ degrees of freedom (Sokal \& Rohlf 1981), where $t=$ (predicted $\mathrm{H}_{\mathrm{S}}$ - observed $\left.\mathrm{H}_{\mathrm{S}}\right) / \hat{S}_{Y}$, and $n$ was the number of observations used to generate the regression.

To investigate the evolutionary (genealogical) relationships among yellowfin goby haplotypes, we constructed a statistical parsimony network (Templeton et al. 1992) using the program TCS v1.13 (Clement et al. 2000). The method was chosen because the phylogenetic relationships among intraspecific data, which typically contains very similar sequences present in multiple copies, is often better represented as a network rather than as a bifurcating tree (Posada \& Crandall 2001).

\section{RESULTS}

\section{Haplotype determination}

We sequenced the entire mitochondrial DNA control region (986 base pairs) of 108 yellowfin goby from northern California (i.e. San Francisco Bay = SFB), 53 from southern California also collected over $2 \mathrm{yr}$, and 55 from Japan collected in a single year (Table 2). The 55 Japan specimens were a mixture of specimens from the 3 collection sites, Tokyo Bay (26), Miyagi (15) and Fukushima (14). Our aim was to generate a geographically diversified Japan sample to compare with the 2 California samples. We found 80 distinct haplotypes among all locations and years sampled (Table 2). The full set of 80 sequences has been deposited in GenBank under accession numbers AY854981-AY855060. About one-fifth of the haplotypes $(21.3 \%)$ were shared among 2 or more samples but most were seen only within the sample where discovered. 


\begin{tabular}{|c|c|c|c|c|c|c|c|c|c|c|}
\hline 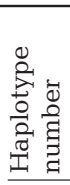 & 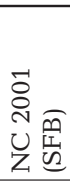 & 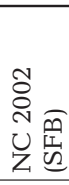 & 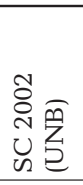 & 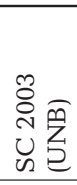 & 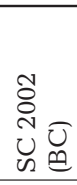 & 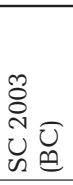 & 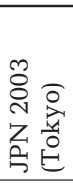 & 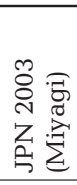 & 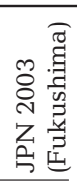 & $\begin{array}{l}\text { Table 2. Acanthogobius flavimanus. Frequency } \\
\text { distribution of yellowfin goby mtDNA haplotypes } \\
\text { determined from full control region sequences, } \\
\text { among sampling localities and years. Locality and } \\
\text { year of samples head the columns. NC: northern } \\
\text { California: SC: southern California: JPN: Japan. }\end{array}$ \\
\hline$\frac{1}{2}$ & 10 & 9 & - & - & - & - & 2 & - & 1 & California sublocalities as follows: SFB: San Fran- \\
\hline 3 & $\frac{1}{6}$ & 5 & - & - & - & - & 2 & - & - & cisco Bay; UNB: upper Newport Bay; BC: Bolsa \\
\hline $\begin{array}{l}4 \\
5\end{array}$ & 6 & 2 & - & - & - & - & 1 & 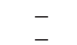 & 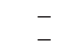 & Chica (Fig. 2). Numbers in columns are the fre- \\
\hline $\begin{array}{l}3 \\
6\end{array}$ & 3 & 2 & - & - & - & - & - & - & $\overline{-}$ & quency of a haplotype found in that sample. For \\
\hline $\begin{array}{l}7 \\
8\end{array}$ & $\begin{array}{l}2 \\
5\end{array}$ & 1 & z & - & $\bar{z}$ & $\begin{array}{l}- \\
-\end{array}$ & $\overline{1}$ & - & $\begin{array}{l}- \\
-\end{array}$ & 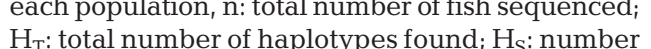 \\
\hline 10 & 1 & 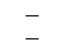 & - & - & - & - & 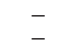 & - & - & of singleton haplotypes, $h$ : haplotype diversity; \\
\hline 11 & 1 & - & - & - & - & & - & - & & $\pi$ : nucleotide diversity \\
\hline
\end{tabular}

\section{Heterogeneity of haplotype frequencies}

There were significant differences in haplotype frequencies among all years and sampling localities (global test of heterogeneity; $\chi^{2}=815.87, \mathrm{p}=0.001$ ); however, pairwise comparisons among sampling localities within populations, and among years within sampling localities, found no significant differences as follows. There were no differences between the 2 yearly samples from northern California (SFB), among sampling localities in southern California, or among the 3 sampling localities in Japan (Fig. 2). No significant difference was found among several comparisons that included the Japan sample from Tokyo Bay as follows: i.e. with the SFB sample from each year, and with samples from 2 southern California localities, upper Newport Bay in 2003 and Bolsa Chica in 2002. Significant differences were found for all other pairwise comparisons. When years and sampling localities were combined for each population, significant differences in haplotype frequencies were found for all pairwise comparisons ( $p<0.001$ in all tests).

\section{Analysis of molecular variance}

An AMOVA also found differences in haplotype composition among sampling localities and years. A large proportion $(57.8 \%)$ of the total observed molecular variance was attributed to differences among sampling localities and years, with an overall $\Phi_{\mathrm{ST}}=0.422(\mathrm{p}<0.001)$. Differences among samples within geographic regions also accounted for a significant portion of the observed molecular variance 
$\left(23.3 \% ; \Phi_{\mathrm{SC}}=0.287 ; \mathrm{p}<0.001\right)$. Pairwise $\Phi_{\mathrm{ST}}$ values indicated significant differences in haplotype composition similar to those found with the heterogeneity tests. Within the northern and southern California populations, respectively, no significant differences were found between sampling locality and/or year (Table 3 ). Among the Japan localities no difference was found between the Miyagi and Fukushima samples, but a significant difference was seen between them and the Tokyo Bay sample. In addition, no significant difference was found between Tokyo Bay and both SFB yearly samples (Table 3 ).

To better elucidate the genetic structure among the different populations, we reorganized the data to reflect the results of the prior AMOVA and heterogeneity tests. Sequences from different years and/or sampling location in northern and southern California were respectively combined to create a single population sample for each area. Among the Japan samples, those from Miyagi and Fukushima were combined (JPN-other), leaving Tokyo Bay separate. A second AMOVA was then performed. Once again, a large proportion $(52.9 \%)$ of the observed molecular variance was due to differences among the 4 populations, with an overall $\Phi_{\mathrm{ST}}=0.471(\mathrm{p}<0.001)$. A significant portion of the variance was again attributed to differences among populations within regions $\left(38.2 \% ; \Phi_{\mathrm{SC}}=0.419\right.$; $\mathrm{p}<0.001)$. Pairwise $\Phi_{\mathrm{ST}}$ values among the 4 populations showed a similar pattern as the prior tests; all populations were significantly different from one another, except for SFB and Tokyo Bay (pairwise $\Phi_{\mathrm{ST}}=$ 0.0116; $\mathrm{p}=0.119 ;$ Table 4).

Based on the results of the heterogeneity tests and the 2 AMOVAs, the data were subsequently treated as follows: (1) Northern and southern California populations were kept separate. (2) The Japan population was considered as either a single population (JPN-all), or was treated as 2 groups, Tokyo Bay (JPN-Tokyo) and all other sequences (JPN-other).

\section{Test for reduction of singleton haplotypes}

The number of singleton haplotypes found in northern California (i.e. San Francisco Bay $=$ SFB) was significantly fewer (Table 5) than the number predicted by the singleton haplotype regression from Fig. 1. When separated by year, SFB 2001 had significantly fewer singletons than predicted $(\mathrm{p}=0.0017)$, whereas SFB 2002 very marginally did not $(p=0.052)$. There was no significant difference between the observed and predicted number of singletons in southern California or any Japan sample (Table 5). However, the lower $95 \%$ prediction limit of the regression of Fig. 1 is negative for small values $(<8)$ of total haplotypes, so with only 6 total haplotypes discovered in southern California, there could be no possibility of a positive value falling below the prediction limit.

Table 3. Acanthogobius flavimanus. Below diagonal: Pairwise $\Phi_{\mathrm{ST}}$ values among all sampling localities and years. Above diagonal: $\Phi_{\mathrm{ST}}$ p-values $\left( \pm\right.$ SD from 3000 permutations of the original data set). ${ }^{*}$ : significant values at table-wide $\alpha=0.05$ following sequential Bonferroni correction. NC: northern California; SC: southern California; JPN: Japan. California sublocalities as follows: SFB: San Francisco Bay; UNB: upper Newport Bay; BC: Bolsa Chica; samples size follows sublocality

\begin{tabular}{|c|c|c|c|c|c|c|c|c|c|}
\hline $\begin{array}{l}\text { Locality } \\
\text { and year }\end{array}$ & $\begin{array}{l}\text { NC 2001 } \\
\text { (SFB-64) }\end{array}$ & $\begin{array}{l}\text { NC 2002 } \\
\text { (SFB-44) }\end{array}$ & $\begin{array}{c}\text { SC 2002 } \\
\text { (UNB-17) }\end{array}$ & $\begin{array}{l}\text { SC 2003 } \\
\text { (UNB-11) }\end{array}$ & $\begin{array}{c}\text { SC } 2002 \\
\text { (BC-5) }\end{array}$ & $\begin{array}{l}\text { SC 2003 } \\
(B C-20)\end{array}$ & $\begin{array}{l}\text { JPN } 2003 \\
\text { (Tokyo-26) }\end{array}$ & $\begin{array}{c}\text { JPN } 2003 \\
\text { (Miyagi-15) }\end{array}$ & $\begin{array}{c}\text { JPN } 2003 \\
\text { (Fukushima-14) }\end{array}$ \\
\hline $\begin{array}{l}\text { NC } \\
2001\end{array}$ & - & $\begin{array}{c}0.0826 \\
(0.005)\end{array}$ & $\begin{array}{c}<0.0001^{*} \\
(0.000)\end{array}$ & $\begin{array}{l}<0.0001^{*} \\
(0.000)\end{array}$ & $\begin{array}{c}0.0017^{*} \\
(0.0009)\end{array}$ & $\begin{array}{l}<0.0001^{*} \\
(0.000)\end{array}$ & $\begin{array}{c}0.1018 \\
(0.0056)\end{array}$ & $\begin{array}{l}<0.0001^{*} \\
(0.000)\end{array}$ & $\begin{array}{l}<0.0001^{*} \\
(0.000)\end{array}$ \\
\hline $\begin{array}{l}\mathrm{NC} \\
2002\end{array}$ & 0.0124 & - & $\begin{array}{c}<0.0001^{*} \\
(0.000)\end{array}$ & $\begin{array}{l}<0.0001^{*} \\
(0.000)\end{array}$ & $\begin{array}{c}0.0010^{*} \\
(0.0006)\end{array}$ & $\begin{array}{l}<0.0001^{*} \\
(0.000)\end{array}$ & $\begin{array}{c}0.1114 \\
(0.0058)\end{array}$ & $\begin{array}{l}<0.0001^{*} \\
(0.000)\end{array}$ & $\begin{array}{l}<0.0001^{*} \\
(0.000)\end{array}$ \\
\hline $\begin{array}{l}\mathrm{SC} \\
2002\end{array}$ & 0.2257 & 0.2361 & - & $\begin{array}{c}0.5187 \\
(0.0088)\end{array}$ & $\begin{array}{c}0.1520 \\
(0.0066)\end{array}$ & $\begin{array}{c}0.8694 \\
(0.0063)\end{array}$ & $\begin{array}{l}<0.0001^{*} \\
(0.000)\end{array}$ & $\begin{array}{l}<0.0001^{*} \\
(0.000)\end{array}$ & $\begin{array}{l}<0.0001^{*} \\
(0.000)\end{array}$ \\
\hline $\begin{array}{l}\mathrm{SC} \\
2003\end{array}$ & 0.2308 & 0.2385 & -0.0541 & - & $\begin{array}{c}0.0889 \\
(0.0052)\end{array}$ & $\begin{array}{c}0.8377 \\
(0.0068)\end{array}$ & $\begin{array}{l}<0.0001^{*} \\
(0.000)\end{array}$ & $\begin{array}{c}<0.0001^{*} \\
(0.000)\end{array}$ & $\begin{array}{l}<0.0001^{*} \\
(0.000)\end{array}$ \\
\hline $\begin{array}{l}\mathrm{SC} \\
2002\end{array}$ & 0.2232 & 0.2298 & 0.1669 & 0.2537 & - & $\begin{array}{c}0.0787 \\
(0.0044)\end{array}$ & $\begin{array}{c}0.0023^{*} \\
(0.0008)\end{array}$ & $\begin{array}{c}0.0003^{*} \\
(0.0003)\end{array}$ & $\begin{array}{l}<0.0001^{*} \\
(0.000)\end{array}$ \\
\hline $\begin{array}{l}\mathrm{SC} \\
2003\end{array}$ & 0.2359 & 0.2419 & -0.0478 & -0.0611 & 0.1723 & - & $\begin{array}{l}<0.0001^{*} \\
(0.000)\end{array}$ & $\begin{array}{l}<0.0001^{*} \\
(0.000)\end{array}$ & $\begin{array}{l}<0.0001^{*} \\
(0.000)\end{array}$ \\
\hline $\begin{array}{l}\text { JPN } \\
\text { Tokyo }\end{array}$ & 0.0131 & 0.0146 & 0.1974 & 0.1857 & 0.1828 & 0.2021 & - & $\begin{array}{l}<0.0001^{*} \\
(0.000)\end{array}$ & $\begin{array}{l}<0.0001^{*} \\
(0.000)\end{array}$ \\
\hline $\begin{array}{l}\text { JPN } \\
\text { Miyagi }\end{array}$ & 0.6174 & 0.6245 & 0.6877 & 0.6608 & 0.6697 & 0.6791 & 0.5840 & - & $\begin{array}{c}0.4416 \\
(0.009)\end{array}$ \\
\hline $\begin{array}{l}\text { JPN } \\
\text { Fukushima }\end{array}$ & 0.6451 & 0.6466 & 0.6959 & 0.6656 & 0.6610 & 0.6888 & 0.6048 & -0.0038 & - \\
\hline
\end{tabular}


Table 4. Acanthogobius flavimanus. Below diagonal: pairwise $\Phi_{\mathrm{ST}}$ values among northern and southern California populations (respectively lumped), and Japan populations. Above diagonal: $p$-values ( \pm SD) for pairwise comparisons from 3000 permutations of original data set. *: significant values at table-wide $\alpha=0.05$ after a sequential Bonferroni correction. NC: northern California; SC: southern California; JPN: Japan. California sublocalities as follows: SFB: San Francisco Bay; UNB: upper Newport Bay; BC: Bolsa Chica

\begin{tabular}{|lcccc|}
\hline Population & $\begin{array}{c}\text { NC } \\
\text { (SFB) }\end{array}$ & $\begin{array}{c}\text { SC } \\
\text { (UNB + BC) }\end{array}$ & $\begin{array}{c}\text { JPN } \\
\text { (Tokyo Bay) }\end{array}$ & $\begin{array}{c}\text { JPN-other } \\
\text { (Miyagi + Fukushima) }\end{array}$ \\
\hline NC (SFB) & - & $<0.001^{*}$ & 0.1187 & $<0.001^{*}$ \\
SC (UNB + BC) & 0.2477 & - & $<0.001^{*}$ & $<0.001^{*}$ \\
JPN (Tokyo Bay) & 0.0116 & 0.2402 & - & $<0.001^{*}$ \\
JPN-other (Miyagi + Fukushima) & 0.6314 & 0.7035 & 0.5913 & - \\
\hline
\end{tabular}

Table 5. Acanthogobius flavimanus. Number of observed and predicted singleton mtDNA control region haplotypes in yellowfin goby populations. $t$ is defined as (predicted $\mathrm{H}_{\mathrm{S}}$ - observed $\mathrm{H}_{\mathrm{S}}$ )/prediction $\mathrm{SE}$, and significance $(\mathrm{p}$ ) is the probability of finding a greater $t$-statistic by chance with $\mathrm{df}=13$. $h$ : haplotype diversity; $\pi$ : nucleotide diversity; $\mathrm{H}_{\mathrm{T}}$ : number of haplotypes; $\mathrm{H}_{\mathrm{S}}$ : number of singleton haplotypes. NC: northern California; SC: southern California; JPN: Japan. California sublocalities as follows: SFB: San Francisco Bay; UNB: upper Newport Bay; BC: Bolsa Chica

\begin{tabular}{|c|c|c|c|c|c|c|c|c|c|}
\hline Population & $\mathrm{n}$ & $h$ & $\pi$ & $\mathrm{H}_{\mathrm{T}}$ & Observed $\mathrm{H}_{\mathrm{S}}$ & Predicted $\mathrm{H}_{\mathrm{S}}$ & Prediction SE & $t$ & $\mathrm{p}$ \\
\hline $\mathrm{NC}(\mathrm{SFB})$ & 108 & 0.942 & 0.003 & 43 & 29 & 39.67 & 2.587 & 4.127 & $<0.001$ \\
\hline $\mathrm{SC}(\mathrm{UNB}+\mathrm{BC})$ & 53 & 0.585 & 0.002 & 6 & 3 & 4.41 & 2.734 & 0.515 & 0.307 \\
\hline JPN-all & 55 & 0.985 & 0.007 & 42 & 35 & 38.72 & 2.587 & 1.439 & 0.087 \\
\hline JPN (Tokyo Bay) & 26 & 0.982 & 0.004 & 21 & 17 & 18.71 & 2.643 & 0.646 & 0.265 \\
\hline JPN-other & 29 & 0.966 & 0.004 & 22 & 19 & 19.66 & 2.638 & 0.250 & 0.403 \\
\hline
\end{tabular}

Observed total haplotypes and singletons for all populations were plotted on the haplotype regression in Fig. 1. Both SFB combined (2 yr) and SFB 2001 fell well below the lower $95 \%$ prediction interval of the regression with SFB 2002 nearly on the lower prediction interval. In contrast, southern California and the separated Japan populations were found at or near the regression line. The combined Japan (JPN-all) population fell slightly lower than the regression line, but was still well within the prediction interval for new observations. Using truncated sequences, $h$ values from SFB fell slightly to 0.902 (504 b) and 0.857 (320 b), while the observed numbers of singletons was significantly less than the predicted number $(\mathrm{p}=0.007$ and $\mathrm{p}=0.005$, respectively; Table 6).

\section{Genealogical analysis and sequence divergences}

Most of the 80 haplotypes discovered were connected in the statistical parsimony network to a single haplotype by 5 or fewer mutational steps (Fig. 3). The central haplotype (H1) was the most common one in northern California (i.e. San Francisco Bay = SFB), and was 1 of several common haplotypes in Tokyo Bay, but occurred only once among the other Japan locations. An arbitrarily defined Group A (Fig. 3) mostly consisted of haplotypes found only in SFB and of haplotypes shared between San Francisco and Tokyo bays. It also contained a single haplotype (H70) from
JPN-other. Group B was a mixture of haplotypes from SFB, Tokyo Bay, half of the haplotypes of southern California, as well as haplotypes shared among those populations. Group C contained the remaining haplotypes from southern California connected to the central one from Tokyo Bay. Group D comprised haplotypes that were only found in JPN-other, except for a single Tokyo Bay haplotype (H59). Group D was also distinct from Groups A to $\mathrm{C}$ in that most haplotypes were further removed from the central haplotype (Fig. 3). Average sequence divergences between populations was high (>0.8) for all pairwise comparisons

Table 6. Acanthogobius flavimanus. Influence of sequence length on the number of singleton haplotypes, haplotype diversity $(h)$, and nucleotide diversity $(\pi)$ in the San Francisco Bay population of yellowfin goby. Truncated sequences are comprised of contiguous bases from the left domain of the control region. $\mathrm{H}_{\mathrm{T}}$ : number of haplotypes; $\mathrm{H}_{\mathrm{S}}$ : number of singleton haplotypes

\begin{tabular}{|cccccccc|}
\hline $\begin{array}{c}\text { No. of } \\
\text { bases }\end{array}$ & $h(\mathrm{SD})$ & $\pi(\mathrm{SD})$ & $\mathrm{H}_{\mathrm{T}}$ & $\begin{array}{c}\text { Observed } \\
\mathrm{H}_{\mathrm{S}}\end{array}$ & $\begin{array}{c}\text { Predicted } \\
\mathrm{H}_{\mathrm{S}}\end{array}$ & $\mathrm{p}$ \\
\hline 985 & 0.942 & 0.0034 & 43 & 29 & 39.67 & $<0.001$ \\
& $(0.013)$ & $(0.0020)$ & & & & \\
504 & 0.902 & 0.0046 & 27 & 17 & 25.38 & 0.007 \\
& $(0.014)$ & $(0.0029)$ & & & & \\
320 & 0.857 & 0.0059 & 18 & 8 & 15.85 & 0.005 \\
& $(0.020)$ & $(0.0038)$ & & & & \\
\hline
\end{tabular}




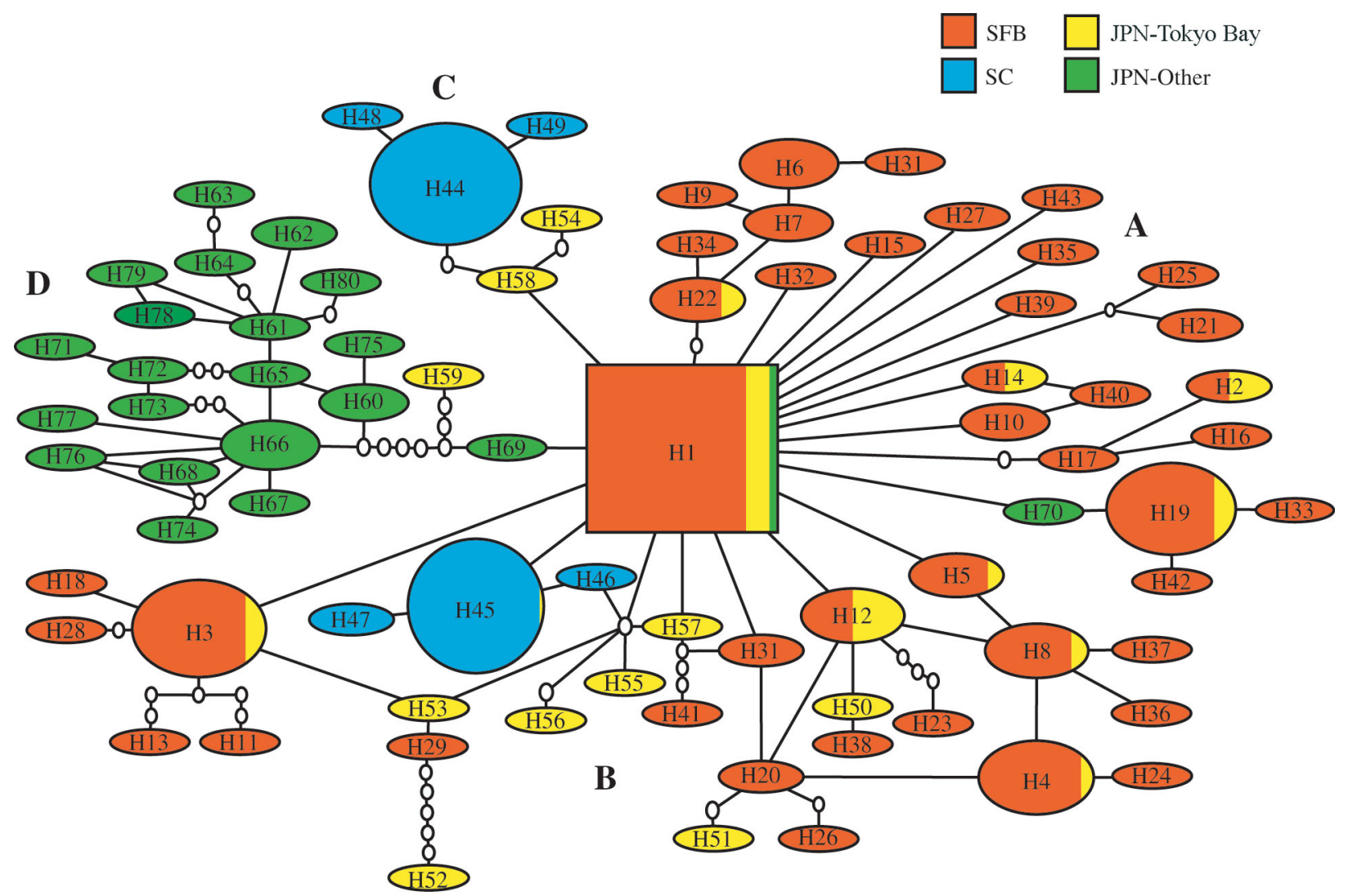

Fig. 3. Acanthogobius flavimanus. Statistical parsimony network of yellowfin goby sequence haplotypes found in California and Japan populations. Lines connecting haplotypes represent single nucleotide differences; small circles represent hypothetical intermediary haplotypes not observed in the population samples. Group A consists mainly of San Francisco Bay (SFB) and Tokyo Bay haplotypes, with a single non-Tokyo Bay Japan haplotype; Group B is a mixture of SFB, SC, and Tokyo Bay haplotypes; Group C contains the remaining SC haplotypes and 2 Tokyo Bay haplotypes; Group D contains all remaining haplotypes from the non-Tokyo Bay Japan samples, and a single Tokyo Bay haplotype

except for SFB and Tokyo Bay (Table 7), which were not significantly different from one another $\left(\pi_{12}=\right.$ 0.033; $\mathrm{p}=0.156)$.

Table 7. Acanthogobius flavimanus. Average sequence divergences among California and Japan populations. Below diagonal: the corrected average numbers of pairwise differences $\left[\pi_{12}-\left(\pi_{1}+\pi_{2}\right) / 2\right]$ among control region sequences between populations as calculated in Arlequin (Nei \& Li 1979, Schneider et al. 2000); diagonal elements (grey) are average number of pairwise differences within populations $(\pi)$; above diagonal: estimated p-values of pairwise comparisons from 3000 permutations of the data set. ${ }^{*}$ Values that are statistically significant at table-wide $\alpha=0.05$ after a sequential Bonferroni correction

\begin{tabular}{|lcccc|}
\hline Population & $\begin{array}{c}\text { NC } \\
\text { (SFB) }\end{array}$ & $\begin{array}{c}\text { SC } \\
(\mathrm{UNB}+\mathrm{BC})\end{array}$ & $\begin{array}{c}\text { JPN } \\
\text { (Tokyo Bay) }\end{array}$ & $\begin{array}{l}\text { JPN- } \\
\text { other }\end{array}$ \\
\hline NC (SFB) & 3.365 & $<0.001^{*}$ & 0.156 & $<0.001^{*}$ \\
SC (UNB + BC) & 0.979 & 2.113 & $<0.001^{*}$ & $<0.001^{*}$ \\
JPN (Tokyo Bay) & 0.033 & 0.831 & 3.871 & $<0.001^{*}$ \\
JPN-other & 6.041 & 6.708 & 5.833 & 4.175 \\
\hline
\end{tabular}

\section{DISCUSSION}

Population-genetic bottlenecks, either recent or historic, are widely posited to account for low observed values of genetic diversity $(h)$ and sometimes nucleotide diversity $(\pi)$ over a wide range of taxa (Bernatchez et al. 1989, Bucklin \& Wiebe 1998, Grant \& Bowen 1998, Glenn et al. 1999, 2002, Pang et al. 2003). Conversely, relatively high values of $h$ imply the opposite: the absence of recent genetic bottlenecks (Grant \& Bowen 1998). Lacking demographic information, there is difficulty distinguishing bottlenecks from other forces acting to reduce variability (e.g. low intrinsic variability or mutation rate, selective sweep of deleterious alleles at linked loci). Knowing the history of population size changes allows stronger inferences about present-day patterns of genetic diversity, particularly in cases of suspected or proposed genetic bottlenecks.

The colonization history of yellowfin goby in California suggests marked changes in size of the invading populations. Geographic populations in northern and 
southern California were apparently small for several years after colonization (Brittan et al. 1963, Haaker 1979), then dramatically increased in size (Brittan et al. 1970, Meng et al. 1994). Expansion and spread of individuals away from the apparent introduction sites (Brittan et al. 1970, Williams et al. 1998) suggested that the 2 populations were largely self-replenishing. Apparently different introduction times, as well as significant differences in haplotype frequencies and sequence divergences (Tables 3, 4 \& 7), now indicate that yellowfin goby in California likely stem from 2 separate invasions, and presently experience negligible, if any, gene flow between northern and southern California.

The traditional index of haplotype diversity, $h$, suggests that only the southern California population experienced significant reduction in genetic diversity compared to its supposed source population or to natural populations of marine fishes 'at equilibrium' (Table 1). Conversely, the $h$ value for the sequences from San Francisco Bay yellowfin goby was similar to, although less than, values seen in Japan, as well as those reported for populations not thought to have experienced a recent bottleneck, including 2 native California gobies, Clevelandia ios and Gillichthys mirabilis, of the same estuaries (Table 1).

In contrast to $h$, the observed numbers of singleton haplotypes for both the full and truncated sequences from San Francisco Bay were significantly fewer than predicted (Tables 5 \& 6), with an important point being that their numbers were predictable by our approach. The lack of singleton haplotypes is especially evident from the truncated sequences that were closer in length to those on which the regression (Fig. 1) was based (Table 6). We suggest that evidence for a genetic bottleneck in the San Francisco Bay population is seen in the reduced number of observed singleton haplotypes (Tables 1, $5 \& 6$ ), although corroboration from other genetic measures is needed for confirmation. The loss agrees with theoretical predictions of the fate of rare mtDNA haplotypes following a bottleneck (Avise et al. 1984, Maruyama \& Fuerst 1985).

The southern California population showed reduction in both $h$ and singleton fraction compared to most of the studies from the regression (Table 1), although there was no significant difference between observed and expected numbers of singletons. The southern California population had the same number of total and singleton haplotypes as Microstomus achne (Table 1), but 5 times more yellowfin goby were sequenced. Most of the reference studies (13 out of 15) found more than 10 haplotypes compared to the 6 that we found. With so few, as stated above, there could be no possibility of a positive value falling below the prediction limit of the regression of Fig. 1.
The loss of singletons from San Francisco Bay and the low haplotype diversity in southern California supports our hypothesis of a genetic bottleneck occurring in concert with a demographic one during colonization. Their relative severities apparently differed, with the southern California population having since experienced more drift, and perhaps some sequence divergence (Fig. 3, Table 7) generating new haplotypes, if the 2 invasive populations indeed had the same source.

Introduction to California was thought to have occurred by the transport of eggs or larvae by transoceanic shipping vessels, presumably from Japan (Brittan et al. 1963, 1970), with a similar method proposed for its introduction to Australian waters (Hoese 1973). Given such a mode of introduction, the data would suggest a yellowfin goby population, as represented genetically by the Tokyo Bay sample, as the source of the northern California population, specifically in San Francisco Bay and the Sacramento River delta area. No significant differences in haplotype frequencies or sequence divergences were found between San Francisco and Tokyo Bay (Tables 3, 4 \& 5). Several haplotypes were shared between these locations, with a number of haplotypes being singletons in Tokyo Bay but which are now common haplotypes in San Francisco Bay. Moreover, the common haplotypes from Tokyo Bay were present in multiple copies in San Francisco Bay (Table 2). The pattern of haplotype frequency is similar to the one seen between introduced populations of striped bass Morone saxatilis on the Pacific Coast and its source population in the Hudson River (Waldman et al. 1998).

Although significant differences in haplotype mutations and frequency were seen between southern California and Tokyo Bay, a singleton from Tokyo Bay was the most common haplotype in southern California. The reduced number of total haplotypes in southern California could be due to extreme genetic drift associated with the fragmented estuarine habitat in southern California, the likely small overall size of the population there, as well as the stochastic nature of larval recruitment in marine fishes. Recurrent invasions do not seem likely factors in shaping the pattern of genetic diversity in southern California yellowfin goby. If multiple invasions had occurred, one would predict a greater proportion of shared haplotypes between the source and introduced populations, as well as an increased proportion of multiple-copy haplotypes in introduced populations (Avise et al. 1984, Maruyama \& Fuerst 1985).

Our results provide tentative support for a Japan origin of both northern and southern California populations of yellowfin goby, pending wider population sampling in East Asia. As seen in the statistical parsimony network (Fig. 3), California haplotypes were mutation- 
ally close to Tokyo Bay haplotypes in Groups A, B, and $\mathrm{C}$ of the network, and distinct from the other Japan haplotypes of Miyagi and Fukushima. The pool of founder haplotypes introduced to California was an apparent subset of a large group of related ones within a geographic population range that included Tokyo Bay and its tidal tributaries.

In conclusion, our findings reveal a significant loss of mtDNA alleles in the yellowfin goby population of San Francisco Bay compared to Tokyo Bay, consistent with the historical demography of its colonization there more than $40 \mathrm{yr}$ ago, even in the evident absence of strong reductions in the traditional index of haplotype diversity. Similarities in haplotype frequencies and mutational differences between goby from San Francisco Bay and Tokyo Bay, Japan, support the present suggestion that Tokyo Bay is a likely source of the introduced California populations, although wider population sampling in East Asia is warranted for confirmation.

Acknowledgements. We thank K. Hieb and S. Slater of the California Department of Fish and Game (CDFG), San Francisco Bay Study, and the Interagency Ecological Program for the San Francisco Estuary, for collecting yellowfin goby in northern California, and J. Scholl and B. Shelton (CDFG) for providing access and support for sampling within Bolsa Chica and upper Newport Bay Ecological Reserves in southern California. We also thank K. Matsuura, K. Shibukawa, and K. Hoishino for hosting our collecting trip to Japan, and J. Allen, T. Wijte, and J. Archie for thoughtful discussion and constructive criticism of the project. Finally, we thank E. Armour, A. Beck, J. Dickens, E. Gallardo, and C. Luzier for general help and support in the lab and field. The research was funded chiefly through grant number S06GM063119 (Subproject 3) from the National Institutes of Health SCORE program to the College of Natural Sciences and Mathematics at California State University, Long Beach; L. Kingsford, program director at Long Beach. We also acknowledge support from the Lerner-Grey Fund for Marine Research (American Museum of Natural History) and a Boeing Graduate Fellowship to M.E.N., and the College of Natural Sciences and Mathematics of California State University, Long Beach.

\section{LITERATURE CITED}

Avise JC, Neigel JE, Arnold J (1984) Demographic influences on mitochondrial DNA lineage survivorship in animal populations. J Mol Evol 20:99-105

Baltz DM (1991) Introduced fishes in marine systems and inland seas. Biol Conserv 56:151-177

Bernatchez L (2001) The evolutionary history of brown trout (Salmo trutta L.) inferred from phylogeographic, nested clade, and mismatch analyses of mitochondrial DNA variation. Evolution 55:351-379

Bernatchez L, Dodson JJ, Boivin S (1989) Population bottlenecks: influence on mitochondrial DNA diversity and its effect in coregonine stock discrimination. J Fish Biol 35: 233-244

Bowen BW, Grant WS (1997) Phylogeography of the sardines (Sardinops spp.): assessing biogeographic models and pop- ulation histories in temperate upwelling zones. Evolution 51:1601-1610

Brittan MR, Albrecht AB, Hopkirk JD (1963) An oriental goby collected in the San Joaquin River Delta near Stockton, California. Calif Fish Game 49:302-304

Brittan MR, Hopkirk JD, Connors JD, Martin M (1970) Explosive spread of the oriental goby Acanthogobius flavimanus in the San Francisco Bay-Delta region of California. Proc Calif Acad Sci 38:207-214

Bucklin A, Wiebe PH (1998) Low mitochondrial diversity and small effective population sizes of the copepods Calanus finmarchicus and Nannocalanus minor: possible impact of climatic variation during recent glaciation. J Hered 89: 383-392

Carlton JT, Geller JB (1993) Ecological roulette: the global transport of nonindigenous marine organisms. Science 261:78-82

Chakraborty R, Nei M (1977) Bottleneck effects on average heterozygosity and genetic distance with the stepwise mutation model. Evolution 31:347-356

Clement M, Posada D, Crandall KA (2000) TCS: a computer program to estimate gene genealogies. Mol Ecol 9: $1657-1659$

Cohen AN, Carlton JT (1998) Accelerating invasion rate in a highly invaded estuary. Science 279:555-558

Cornuet JM, Luikart G (1996) Description and power analysis of two tests for detecting recent population bottlenecks from allele frequency data. Genetics 144:2001-2014

Dawson MN, Louie KD, Barlow M, Jacobs DK, Swift CC (2002) Comparative phylogeography of sympatric sister species, Clevelandia ios and Eucyclogobius newberryi (Teleostei, Gobiidae), across the California Transition Zone. Mol Ecol 11:1065-1075

Excoffier L, Smouse PE, Quattro JM (1992) Analysis of molecular variance inferred from metric distance among DNA haplotypes: application to human mitochondrial DNA restriction data. Genetics 131:479-491

Garza JC, Williamson EG (2001) Detection of reduction in population size using data from microsatellite loci. Mol Ecol 10:305-318

Gibbs JP (2001) Demography versus habitat fragmentation as determinants of genetic variation in wild populations. Biol Conserv 100:15-20

Glenn TC, Stephan W, Braun MJ (1999) Effects of a population bottleneck on whooping crane mitochondrial DNA variation. Conserv Biol 13:1097-1107

Glenn TC, Staton JL, Vu AT, Davis LM, Alvarado-Bremer JM, Rhodes WE, Brisbin IL, Sawyer RH (2002) Low mitochondrial DNA variation among American alligators and a novel non-coding region in crocodilians. J Exp Zool 294:312-324

Gold JR, Sun F, Richardson LR (1997) Population structure of red snapper from the Gulf of Mexico as inferred from analysis of mitochondrial DNA. Trans Am Fish Soc 126: 386-396

Goodbred CO, Graves JE (1996) Genetic relationships among geographically isolated populations of bluefish (Pomatomus saltatrix). Mar Freshw Res 47:347-355

Grant WS, Bowen BW (1998) Shallow population histories in deep evolutionary lineages of marine fishes: insights from sardines and anchovies and lessons for conservation. J Hered 89:415-426

Haaker PL (1979) Two Asiatic gobiid fishes, Tridentiger trigonocephalus and Acanthogobius flavimanus, in Southern California. Bull South Calif Acad Sci 78:56-61

Hauser L, Adcock GJ, Smith PJ, Bernal-Ramirez JH, Carvalho GR (2002) Loss of microsatellite diversity and low effective 
population size in an overexploited population of New Zealand snapper (Pagrus auratus). Proc Natl Acad Sci USA 99:11742-11747

Hewitt G (2000) The genetic legacy of the Quaternary ice ages. Nature 405:907-913

Hoelzel AR (1999) Impact of population bottlenecks on genetic variation and the importance of life-history; a case study of the northern elephant seal. Biol J Linn Soc 68:29-39

Hoese DF (1973) The introduction of the gobiid fishes Acanthogobius flavimanus and Tridentiger trigonocephalus into Australia. Koolewong 2:3-5

Jager HI, Chandler JA, Lepla KB, Van Winkle W (2001) A theoretical study of river fragmentation by dams and its effects on white sturgeon populations. Environ Biol Fish 60:347-361

Kai Y, Nakayama K, Nakabo T (2002) Genetic differences among three colour morphotypes of the black rockfish, Sebastes inermis, inferred from mtDNA and AFLP analyses. Mol Ecol 11:2591-2598

Kimura M, Crow JF (1964) The number of alleles that can be maintained in a finite population. Genetics 49:725-738

Lever C (1996) Naturalized fishes of the world. Academic Press, San Diego, CA

Luikart G, Allendorf FW, Cornuet JM, Sherwin WB (1998) Distortion of allele frequency distributions provides a test for recent population bottlenecks. J Hered 89:238-247

Luzier CW, Wilson RR Jr (2004) Analysis of mtDNA haplotypes of kelp bass tests for sibling-dominated recruitment near marine protected areas of the California Channel Islands. Mar Ecol Prog Ser 277:221-230

Maruyama T, Fuerst PA (1985) Population bottlenecks and nonequilibrium models in population genetics. II. Number of alleles in a small population that was formed by a recent bottleneck. Genetics 111:675-689

Meng L, Moyle PB, Herbold B (1994) Changes in abundance and distribution of native and introduced fishes of Suisun Marsh. Trans Am Fish Soc 123:498-507

Myers RA, Worm B (2003) Rapid worldwide depletion of predatory fish communities. Nature 423:280-283

Nei M (1987) Molecular evolutionary genetics. Columbia University Press, New York

Nei M, Li WH (1979) Mathematical model for studying genetic variation in terms of restriction endonucleases. Proc Natl Acad Sci USA 76:5269-5273

Nei M, Maruyama T, Chakraborty R (1975) The bottleneck effect and genetic variability in populations. Evolution 29:1-10

Ovenden JR, Street R (2003) Genetic population structure of mangrove jack, Lutjanus argentimaculatus (Forsskal). Mar Freshw Res 54:127-137

Pang J, Hoelzel AR, Song Y, Zeng Z, Zhang Y (2003) Lack of mtDNA control region variation in Hainan Eld's deer: consequence of a recent population bottleneck? Conserv Genet 4:109-112

Posada D, Crandall KA (2001) Intraspecific gene genealogies: trees grafting into networks. Trends Ecol Evol 16:37-45

Rice WR (1989) Analyzing tables of statistical tests. Evolution 43:223-225

Riginos C, Nachman MW (2001) Population subdivision in marine environments: the contributions of biogeography, geographical distance and discontinuous habitat to genetic differentiation in a blennioid fish, Axoclinus nigricaudus. Mol Ecol 10:1439-1453

Roff DA, Bentzen P (1989) The statistical analysis of mitochondrial DNA polymorphisms: chi-squared and the problem of small samples. Mol Biol Evol 6:539-545
Sambrook J, Fritsch EF, Maniatis T (1989) Molecular cloning: a laboratory manual. Cold Spring Harbor Laboratory, Cold Spring Harbor, NY

Sang TF, Chang HY, Chen CT, Hui CF (1994) Population structure of the Japanese eel, Anguilla japonica. Mol Biol Evol 11:250-260

Schneider S, Roessli D, Excoffier L (2000) Arlequin: a software for population genetics data analysis. Genetics and Biometry Lab, Department of Anthropology, University of Geneva, Geneva

Sokal RR, Rohlf FJ (1981) Biometry. WH Freeman, New York

Stefanni S, Thorley JL (2003) Mitochondrial DNA phylogeography reveals the existence of an Evolutionary Significant Unit of the sand goby Pomatoschistus minutus in the Adriatic (Eastern Mediterranean). Mol Phylogenet Evol 28:601-609

Stepien CA (1999) Phylogeographical structure of the Dover sole Microstomus pacificus: the larval retention hypothesis and genetic divergence along the deep continental slope of the northeastern Pacific Ocean. Mol Ecol 8: 923-939

Stepien CA, Faber JE (1998) Population genetic structure, phylogeography and spawning philopatry in walleye (Stizostedion vitreum) from mitochondrial DNA control region sequences. Mol Ecol 7:1757-1769

Stepien CA, Dillon AK, Patterson AK (2000) Population genetics, phylogeography, and systematics of the thornyhead rockfishes (Sebastolobus) along the deep continental slopes of the North Pacific Ocean. Can J Fish Aquat Sci 57:1701-1717

Tajima F (1989) The effect of change in population size on DNA polymorphism. Genetics 123:597-601

Tamura K (1992) Estimation of the number of nucleotide substitutions when there are strong transition-transversion and $\mathrm{G}+\mathrm{C}$ content biases. Mol Biol Evol 9:678-687

Tautz D (1989) Hypervariability of simple sequences as a general source of polymorphic DNA markers. Nucleic Acids Res 17:6463-6471

Templeton AR, Crandall KA, Sing CF (1992) A cladistic analysis of phenotypic associations with haplotypes inferred from restriction endonuclease mapping and DNA sequence data. III. Cladogram estimation. Genetics 132: 619-633

Tringali MD, Wilson Jr RR (1993) Differences in haplotype frequencies of mtDNA of the Spanish sardine Sardinella aurita between specimens from the eastern Gulf of Mexico and southern Brazil. Fish B-NOAA 91:362-370

Waldman JR, Bender RE, Wirgin II (1998) Multiple population bottlenecks and DNA diversity in populations of wild striped bass, Morone saxatilis. Fish B-NOAA 96:614-620

Watterson GA (1984) Allele frequencies after a bottleneck. Theor Popul Biol 26:387-407

Weber J, Wong C (1993) Mutation of human short tandem repeats. Hum Mol Genet 2:1123-1128

Weir BS (1996) Genetic data analysis. Sinaeur Associates, Sunderland, MA

Williams GD, Desmond JS, Zedler JB (1998) Extension of two nonindigenous fishes, Acanthogobius flavimanus and Poecilia latipinna, into San Diego Bay marsh habitats. Calif Fish Game 84:1-17

Wirgin I, Waldman JR, Rosko J, Gross R, Collins MR, Rogers SG, Stabile J (2000) Genetic structure of Atlantic sturgeon populations based on mitochondrial DNA control region sequences. Trans Am Fish Soc 129:476-486

Zaykin DV, Pudovkin AI (1993) Two programs to estimate significance of chi-square values using pseudo-probability test. J Hered 84:152

Submitted: June 11, 2004; Accepted: December 23, 2004

Proofs received from author(s): June 21, 2005 